\title{
Enhanced Accumulation of Scopoletin in Cell Suspension Culture of Spilanthes acmella Murr. Using Precursor Feeding
}

\author{
Mohammad Abyari ${ }^{1}$, Nasrin Nasr ${ }^{2}$, Jahad Soorni ${ }^{3 *}$, Deokule Sadhu ${ }^{1}$ \\ ${ }^{1}$ University of Pune - Department of Botany Pune India; ${ }^{2}$ Department of biology, Payame Noor University (PNU), \\ Tehran, Iran; ${ }^{3}$ Department of Plant Breeding and Biotechnology, Sari Agricultural Sciences and Natural Resources \\ University (SANRU), Mazandaran, Iran.
}

\begin{abstract}
In this study, the various concentrations of casein hydrolysate (25, 50, 75, $100 \mathrm{mg} / \mathrm{L})$ and L-phenylalanine (50, 100, 150, $200 \mu M / l)$ were incorporated in MS containing $15 \mu M$ BA plus $5 \mu M$ 2,4-D for enhancement of secondary metabolites in cell culture of Spilanthes acmella. The presence of casein hydrolysate in the nutrient medium improved the growth of cell biomass and the production of scopoletin. The addition of casein hydrolysate up to 75 $\mathrm{mg} / \mathrm{L}$ stimulated the accumulation of scopoletin, but increasing excess $75 \mathrm{mg} / \mathrm{L}$ the level of casein hydrolysate reduced the production of scopoletin. The addition of L-phenylalanine in the nutrient medium was found to be more effective for production of secondary metabolite in $\mathrm{S}$. acmella. The addition of $50 \mu \mathrm{M} / \mathrm{L}$ of L-phenylalanine in the medium increased scopoletin content to $27.12 \pm 0.58 \mu \mathrm{g} / \mathrm{g}$ dry weight, compared to the scopoletin content of control at $7.89 \pm 0.61 \mu \mathrm{g} / \mathrm{g}$ dry weight. The highest accumulation of scopoletin was observed in the $100 \mu \mathrm{M} / \mathrm{L} \mathrm{L-}$ phenylalanine in cell suspension, which was 4.51 times more than the control. As a result, using moderate concentration of L-phenylalanine was ideal for the production of scopoletin. In general, casein hydrolysate was more effective than L-phenylalanine for production of scopoletin and growth of cell biomass in the cell culture of S. acmella.
\end{abstract}

Key words: Casein hydrolysate, L-phenylalanine, precursor, scopoletin, Spilanthes acmella

"Authors for correspondence: d.soorni@gmail.com 


\section{INTRODUCTION}

Spilanthes acmella Murr. (Asteraceae) is commonly known as toothache plant, suptichada, dandasulakhna danduri in Sanskrit, pellitary in English and akarkara in Hindi. About 60 species of Spilanthes have been reported from various parts of world, and they are mostly perennials of warmer climate (DAS 2014). Spilanthes acmella, however, is an annual hairy herb $32-60 \mathrm{~cm}$ tall, with numerous stems and marigold flowers accumulated in heads (Bunyapraphatsara and Chokechareunporn 1999).

The plant has various applications in pharmaceuticals such as an anti-toothache pain relief(Singh and Chaturvedi 2012), swelling and gum infections (Pandey et al. 2007), periodontosis (Adler 2006), and in mouthwashes (Shimada and Gomi 1995). In addition, its extract is an active component added to the body as beauty-care cosmetics for fast-acting muscle relaxant to accelerate repair of functional wrinkles (Belfer 2007). The plant extract was also used for stimulating, reorganizing, and strengthening the collagen network in anti-age applications such as anti-wrinkle cream formulations (Schubnel 2007; Demarne and Passaro 2008). The herb exhibits general immunomodulator properties when used internally to boost the production of leukocytes and antiviral interferon, as well as to promote phagocytosis (Yoganarasimhan 2000).

$S$. acmella contains a wide diversity of biologically active secondary metabolites such as scopoletin (6-methoxy-7-hydroxycoumarin), which is one of its powerful ingredients and belong to coumarins, a class of phenolic secondary metabolites. Coumarins are derived from the phenylpropanoid pathway in plants, and based on their anti-microbial properties, and production in response various stress events (Chong et al. 2002, Gachon et al. 2004), they are thought to have defense role in plants. Scopoletin has attracted the more attention because of its use in the treatment of cardiovascular diseases and as antitumor and antithyroid agent (DAS 2014). In addition to this, scopoletin also possesses antioxidant, antimicrobial, antiinflammatory, antipyretic, and hepatoprotective properties (Taguchi et al. 2001). Scopoletin also has antifungal (against Candida fungi), antihistamine and antiviral properties, as well as in reducing high blood pressure by dilating the blood vessels (Tanton 2008). Scopoletin has been historically used for menstrual cramps with severe lower back and pelvic pains (Hudson 2007).

Plants are valuable sources of a wide range of secondary metabolites used as pharmaceuticals, agrochemicals, flavors, fragrances, colors, biopesticides and food additives. The production of these compounds is often low (less than 1\% dry weight) and depends greatly on the physiological and developmental stages of the plant (Dixon 2001; Oksman-Caldentey and Inzé 2004). Several strategies, such as manipulating the nutrient, optimizing the culture conditions, feeding of precursor and elicitation have been used to substantially improve the yields of secondary metabolites in plan cell cultures (Ramachandra Rao and Ravishankar 2002). Other techniques such as hairy root culture, biotransformation, immobilization, and elicitations are also applied for the increased production of secondary metabolites. On the basis of the knowledge of the biosynthetic pathways, several organic compounds have been added to the culture medium in order to increase the synthesis of secondary metabolites. The exogenous supply of a biosynthetic precursor to culture medium may enhance the yield of the desired product. This approach is more useful when the precursors are inexpensive. In the present study, we report the effect of casein hydrolysate and L-phenylalanine on the growth of cell biomass and production of scopoletin in cell culture of Spilanthes acmella. To the best of our knowledge, this is the first report on using of organic supplements for enhancement of production of scopoletin in the species.

\section{MATERIAL AND METHODS}

\section{Plant materials and culture conditions}

Spilanthes acmella Murr. plants were obtained from nursery of University of Pune. The plant specimens were got identified and authenticated from the Botanical Survey of India, Regional Office, Western Circle - Pune, 411001 (specimen voucher number- MAET2).

Callus culture was developed from leaf explant of the aseptically germinated $S$. acmella seedlings (Fig. 1a) and maintained on MS medium supplemented with $15 \mu \mathrm{M}$ 6-benzyladenine plus 5 $\mu \mathrm{M}$ 2,4-dichlorophenoxyacetic acid as growth regulators. The cell culture (Fig. 1c) were exposed to various concentrations of casein hydrolysate and L-phenylalanine. For cell culture experiments, $250 \mathrm{~mL}$ flasks containing $40 \mathrm{~mL}$ medium were 
inoculated with cells. Cell suspensions were incubated on a rotary shaker at $100 \pm 10 \mathrm{rpm}$ at 25 $\pm 2^{\circ} \mathrm{C}$ under $16 \mathrm{~h}-8 \mathrm{~h}$ light-dark regime, using fluorescent lamps at a light intensity of $35 \mu \mathrm{mol} \mathrm{m}^{-}$
${ }^{2} \mathrm{~S}^{-1}$. The cultures were harvested after 28 days and dried in oven to be used for secondary metabolites estimation.
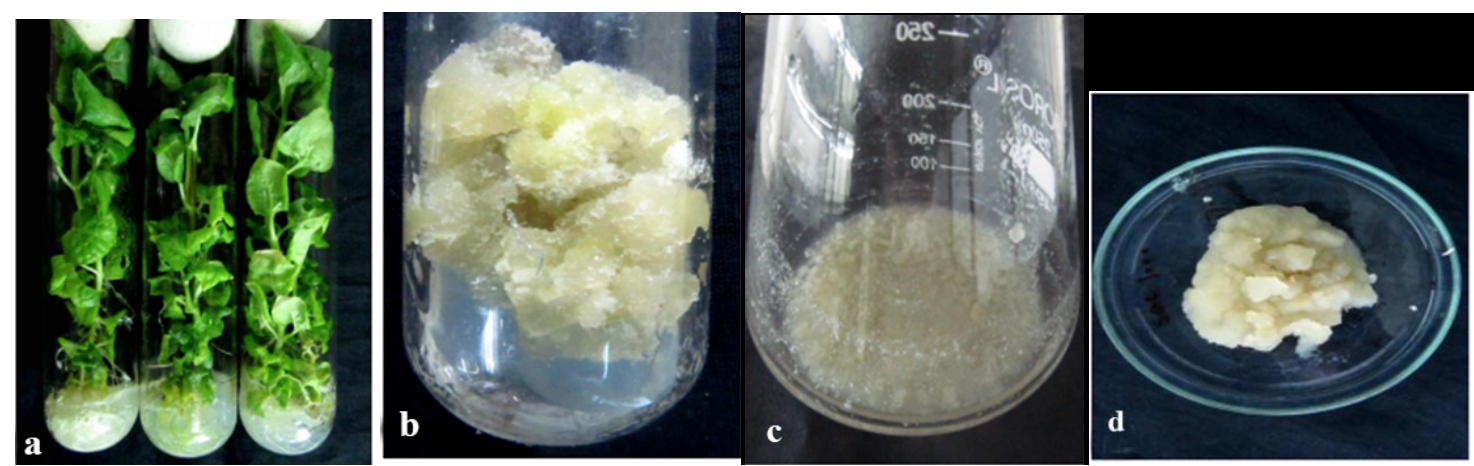

Figure 1- a: Seedling plantlet after 40 days. b: callus on MS plus $15 \mu \mathrm{M}$ BA with $5 \mu \mathrm{M}$ 2,4-D. c: Cell suspension culture. d: Cell biomass.

\section{Establishment of growth and maintenance of cell cultures}

Suspension cultures of S. acmella were developed from leaf-derived callus (Fig. $1 \mathrm{~b}$ and $\mathrm{d}$ ) at stationary phase of growth $(10-12$ days postinoculation). A callus piece ( $1 \mathrm{~g})$ was tenderly broken up in a sterile petri dish to generate 20-30 smaller pieces. The small pieces were transferred aseptically into $250 \mathrm{~mL}$ flasks containing $40 \mathrm{~mL}$ of MS media with $3 \%(\mathrm{w} / \mathrm{v})$ sucrose and $15 \mu \mathrm{M}$ BA plus $5 \mu \mathrm{M} 2,4-\mathrm{D}$. Suspension cultures were routinely subcultured every 2 weeks by transferring into $10 \mathrm{~mL}$ of the previous culture, to $40 \mathrm{~mL}$ (Murashige and Skoog 1962) medium supplemented with $3 \%(\mathrm{w} / \mathrm{v})$ sucrose, $15 \mu \mathrm{M}$ BA plus $5 \mu \mathrm{M}$ 2,4-D at $\mathrm{pH}$ 5.6. To establish growth and production kinetics, the cultures were harvested and analyzed for biomass and scopoletin content. Dry weight was estimated by centrifuging the harvested suspension cells at 3,000 rpm for 15 min, collecting the cells and drying to constant weight at $60^{\circ} \mathrm{C}$.

\section{L-phenylalanine experiment}

The different concentrations of L-phenylalanine (Sigma) $(50,100,150,200 \mu \mathrm{M})$ were incorporated in cell culture media (MS $+15 \mu \mathrm{M}$ BA plus $5 \mu \mathrm{M}$ 2,4-D). L-phenylalanine was dissolved in distilled water $(0.1-1 \%)$ and then was filter sterilized in the laminar airflow by passing through a Millipore membrane (0.22 Dmpore size) (Millipore Corporation, USA) and added to sterilized (autoclaved) medium when the temperature of cell suspension cultures medium reached $50^{\circ} \mathrm{C}$.

\section{Casein hydrolysate experiment}

The various concentrations of casein hydrolysate (Sigma) $(25,50,75,100 \mathrm{mg} / \mathrm{L})$ were incorporated in $\mathrm{MS}$ containing $15 \mu \mathrm{M} \mathrm{BA}+5 \mu \mathrm{M} 2$, 4-D. Appropriate concentrations of casein hydrolysate were first dissolved in distilled water and added to the medium before setting $\mathrm{pH}$ and sterilization. Its effect on the dry weight and secondary metabolites were investigated. It is noteworthy that the $S$. acmella cultures were developed from leaf-derived callus.

Scopoletin standard was procured from SigmaAldrich. The standard was prepared by dissolving $5 \mathrm{mg}$ of the compound in $5 \mathrm{~mL}$ of HPLC grade methanol. The solution was then stored at $-20^{\circ} \mathrm{C}$. The standard solution was filtered through a 0.20 $\mu \mathrm{m}$ membrane filter before HPTLC analysis and run at least thrice to check the repeatability and precision of results. TLC plates containing fluorescent indicator after derivatization with anisaldehyde/sulphuric acid were examined for scopoletin content in UV-366 nm.

To prepare samples, $500 \mathrm{mg}$ of dried powdered samples were soaked in methanol for $12 \mathrm{~h}$. The methanolic samples were then centrifuged in a high-speed refrigerated centrifuge (R-4C REMI make, India) at 5,000 rpm for $10 \mathrm{~min}$. The supernatant was transferred into a new tube and the residue was re-extracted thrice with $10 \mathrm{~mL}$ methanol. Thereafter, the residue was discarded and the supernatant was pooled, filtered, and evaporated to dryness in a rotatory evaporator (Buchi Rotavapor R-200, Japan) at $40^{\circ} \mathrm{C}$. CAMAG analytical HPTLC system was used for estimation of scopoletin. The methanolic fraction 
thus obtained was redissolved in HPLC grade methanol, filtered through a $0.20 \mu \mathrm{m}$ membrane filter prior to analysis, and aliquots of $10 \mu \mathrm{L}$ of clean solution were injected into HPTLC system with CAMAG TLC scanner3. The developing solvent was toluene: ethyl acetate: formic acid (7:3:1). TLC plates, containing fluorescent indicator after derivatization with anisaldehyde sulphuric acid, were examined for scopoletin content in UV-366 nm. Finally, scopoletin content was calculated by area of standard and area of sample.

\section{Statistical analyses}

For each experiment, three replicates (three flask) were performed. Observations on the dry weight (DW) and scopoletin content were recorded at 8day intervals. Standard error of the mean was calculated and represented as bars in the graph.. The data were analyzed statistically using SPSS software version 16, and differences among treatment means were determined using the least significant difference (LSD) at the 0.05 level of probability.

\section{RESULTS}

Effect of casein hydrolysate on the cell culture The influence of casein hydrolysate on growth and accumulation of scopoletin in cell cultures of Spilanthes acmella are depicted in Figure 2. Significant increase in accumulation of scopoletin was achieved in the cell culture medium supplemented with different concentration of casein hydrolysate $(25,50,75$ and $100 \mathrm{mg} / \mathrm{L})$. Also, casein hydrolysate in 50 and $75 \mathrm{mg} / \mathrm{L}$ concentrations caused a significant increase in cell-biomass.

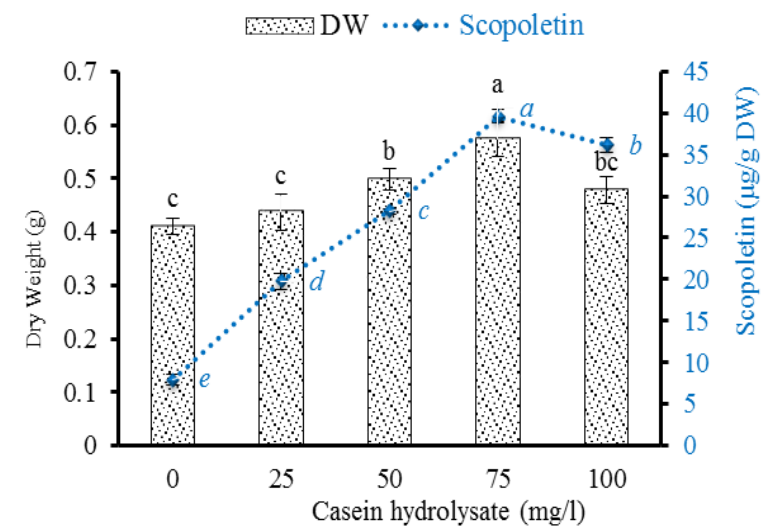

Figure 2 - Effect of different concentrations of casein hydrolysate on dry weigh (DW) and accumulation of scopoletin in cell culture of Spilanthes acmella.

Dry weight of callus that cultured on MS medium with $25 \mathrm{mg} / \mathrm{L}$ was $0.43 \pm 0.03 \mathrm{~g}$, while the biomass of callus produced on control medium was $0.41 \pm 0.03 \mathrm{~g}$. The dry weight of cell biomass gradually increased with the increase in concentration of casein hydrolysate. However, the biomass growth declined with the incorporation of higher concentrations of casein hydrolysate $(>75$ $\mathrm{mg} / \mathrm{L}$ ). The incorporation of 50, 75 and $100 \mathrm{mg} / \mathrm{L}$ casein hydrolysate in cell culture medium increase statistically significant in scopoletin content, while fortification of $75 \mathrm{mg} / \mathrm{L}$ of casein hydrolysate produced the maximum dry weight of the cell culture. It was $0.57 \pm 0.03 \mathrm{~g}$, which was about 1.39 fold more than the control $(0.41 \pm 0.01 \mathrm{~g})$. Results of this part of the experiment revealed that the addition of casein hydrolysate in cell culture was effective for the production of cell biomass and accumulation of scopoletin. Among the different concentrations, addition of $75 \mathrm{mg} / \mathrm{L}$ casein hydrolysate was ideal for scopoletin production.

\section{Effect of l-phenylalanine on cell culture}

The results presented in Figure 3 shows the influence of various concentrations of Lphenylalanine $(0,50,100,150$, and $200 \mu \mathrm{M})$ on the growth (DW) and scopoletin production in cell culture of $S$. acmella. Supplementation of moderate concentrations of L-phenylalanine (100 $150 \mu \mathrm{M})$ in the nutrient medium of the cell culture was statistically effective for growth of cell biomass (Fig. 3). The inclusion of high concentrations of L-phenylalanine was ineffective for stimulation growth of cell biomass. However, 
the inclusion of $100 \mu \mathrm{M}$ L-phenylalanine in cell culture showed highest (with statistically significant differences) growth of cell biomass $(0.451 \pm 0.01 \mathrm{~g})$ and accumulation of scopoletin. The dry weight of cell culture at $150 \mathrm{mg} / \mathrm{L} \mathrm{L}$ phenylalanine concentration was $0.42 \pm 0.01 \mathrm{~g}$. These results showed that the addition of 100 or $150 \mu \mathrm{M} / \mathrm{L}$ L-phenylalanine in cell cultures media was effective for biomass production in $S$. acmella.

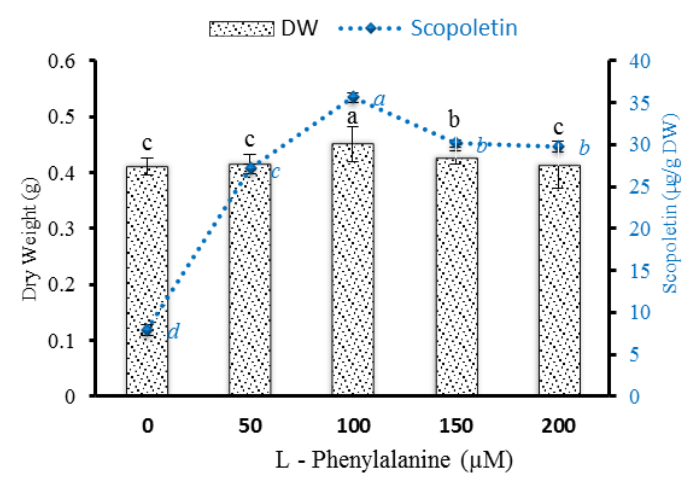

Figure 3- Effect of different concentrations of Lphenylalanine on dry weight (DW) and accumulation of scopoletin in cell culture of Spilanthes acmella.

The inclusion of low concentrations of Lphenylalanine $(50 \mu \mathrm{M})$ resulted in increased scopoletin content by about 3.43 times over the control. Among the different concentrations of Lphenylalanine tested, optimum increase in scopoletin in cell culture $(35.63 \pm 0.56 \mu \mathrm{g} / \mathrm{g}$ DW $)$ was obtained at $100 \mu \mathrm{M}$ L-phenylalanine. These results suggested that the addition of moderate concentration of L-phenylalanine, was beneficial for accumulation of secondary metabolite in cell culture.

\section{DISCUSSION}

Casein hydrolysate is a mixture of amino acids and peptides produced by enzymatic or acid hydrolysis of casein, that obtained by digesting casein with hydrochloric acid. It therefore acts as a good nutrient substrate and is especially suitable for the large-scale cultivation in micropropagation and secondary metabolites production (Kayser and Quax 2007). Casein hydrochloric acid hydrolysate was added to media primarily because of the organic nitrogen and growth-factor components. The increase of secondary metabolites content in cell culture cultivated on media with the addition of casein hydrolysate might be due to its sterols or amino acids content (Heble 1985).

Comparable results of increased secondary metabolite contents were reported in cell culture of Panax ginseng with increased in the concentration of casein hydrolysate ( $\mathrm{Wu}$ et al. 2005). They reported $0.5 \mathrm{~g} / \mathrm{L}$ of casein hydrolysate with combined $0.2 \mathrm{mM}$ sorbitol enhanced saponin yield 3.5-fold over the control. The enhancement of artemisinin production on MS supplemented with $0.5 \mathrm{~g} / \mathrm{L}$ casein hydrolysate in cell cultures of Artemisia annua was reported by Woerdenbag et al. (1993). Addition of casein hydrolysate in genetically transformed cultures of Coleus forskohlii for enhancement of forskolin production was reported by Mukherjee et al. (2000).

Precursor feeding has been a successful approach for enhancement of secondary metabolites in different medicinal plants. In particular feeding of loganin, secologanin and tryptamine has been studied extensively. After feeding geraniol, 10hydroxygeraniol or loganin resulted in a significant increase of tabersonine accumulation (Morgan and Shanks 2000).

Similarly, Namdeo (2004) reported that the effect of tryptophan addition on ajmalicine in Coleus roseus cells cultured in Zenk's production medium, maximum ajmalicine $(310 \mu \mathrm{g} / \mathrm{g}$ dry weight) was recorded in medium with $100 \mathrm{mg} / \mathrm{L}$ tryptophan, followed by 292 and $140 \mu \mathrm{g} / \mathrm{g}$ dry weight ajmalicine in medium with 250 and $50 \mathrm{mg} / \mathrm{L}$ tryptophan. Moreno et al. (1993) studied the effect of feeding different terpenoid precursors on alkaloid production. They observed that the addition of secologanin, its precursor loganin and loganic acid increased the accumulation of ajmalicine and strictosidine.

Among the biotechnological methods, stimulation of metabolic pathways in the cultivated plant cells toward production of a desired compound most likely results in a dramatic increase in secondary metabolite yield (Wang et al. 2001). Scopoletin originates from phenylalanine, an upstream metabolic precursor through coumarins biosynthetic pathway. The addition of phenylalanine is expected to increase the level of targeted compounds (Shinde et al. 2009).

The results indicated that addition of high level of L-phenylalanine did not improve cell biomass in cell culture. The incorporation of L-phenylalanine in the nutrient medium was found to be more effective for the production of secondary metabolite in $S$. acmella. The addition of $50 \mu \mathrm{M} / \mathrm{L}$ 
of L-phenylalanine in the medium increased scopoletin content to $27.12 \pm 0.58 \mu \mathrm{g} / \mathrm{g}$ D.W, while scopoletin content of control was $7.89 \pm$ $0.61 \mu \mathrm{g} / \mathrm{g}$ D.W. The highest accumulation of scopoletin was detected at $100 \mu \mathrm{M} / \mathrm{L} \quad \mathrm{L}$ phenylalanine concentration in cell suspension, which was 4.51 times more than the control. As results using moderate concentrations of Lphenylalanine was ideal for the production of scopoletin. By contrast, higher levels of Lphenylalanine did not improve the accumulation of scopoletin.

Similar results on the inclusion of L-phenylalanine in the medium on cell culture of different plants were reported previously (Cusidó et al. 1999) (Brincat et al. 2002). The addition of $0.2 \mathrm{Mm} / \mathrm{L}$ of L-phenylalanine to cell culture of Cistanche deserticola resulted in $75 \%$ higher production of phenylethanoid glycosides, compared with the cell culture without precursors (Ouyang et al. 2005). Paclitaxel yields in the cell culture of Taxus cuspidata were improved up to six times by the addition L-phenylalanine and other potential paclitaxel side-chain precursors (e.g., benzoic acid, $\mathrm{N}$-benzoylglycine and serine) (Fett-Neto and DiCosmo 1996). The present study and previous reports suggest that the L-phenylalanine amino acid has effective role for production of secondary metabolites in cell culture of different plant species.

Singh and Chaturvedi (2010) presented the first report on quantification of scopoletin from the leaves of in vitro and field-grown plants of $S$. acmella. Their study revealed that even the uninfected leaves of Spilanthes could accumulate the scopoletin. They compared the scopoletin content in the tissue-cultured plants of Spilanthes produced from plants with known scopoletin content. These findings open up the possibility of producing Spilanthes plants with the desired metabolite content which will help the pharmaceutical industry to achieve better output by using superior quality raw materials.

Dandin et al. (2014) reported that in vitroregenerated plants of Spilanthes oleracea $\mathrm{L}$. had higher amounts (mean $=3.42 \mu \mathrm{g} \mathrm{g}^{-1} \mathrm{DW}$ ) of scopoletin compared to in vivo plants (range 0.01 $\left.3.04 \mu \mathrm{g} \mathrm{g}^{-1} \mathrm{DW}\right)$.

\section{CONCLUSIONS}

Among two additives precursors and organic supplements, L-phenylalanine and casein hydrolysate, the latter was found to be the most efficient enhancer for the stimulation of bioaccumulation of scopoletin in $S$. acmella. Therefore, it could be used industrially to produce higher yields of coumarins compounds in this species. In conclusion, our results demonstrate that the addition of organic supplements to cell cultures is quite effective for large-scale biosynthesis and constant production of scopoletin.

\section{REFERENCES}

Adler RJ, inventor; Google Patents, assignee. Compositions for the acute and/or long term treatment of periodontal diseases. USA2006 Sep 17, 2009.

Belfer WA, inventor; Google Patents, assignee. Cosmetic composition to accelerate repair of functional wrinkles. USA2007.

Brincat MC, Gibson DM, Shuler ML. Alterations in Taxol production in plant cell culture via manipulation of the phenylalanine ammonia lyase pathway. Biotechnology Progress. 2002;18(6):11491156.

Bunyapraphatsara N, Chokechareunporn O. Tradition medicinal plants. Prachachon: Bangkok1999.

Chong J, Baltz R, Schmitt C, Beffa R, Fritig B, Saindrenan P. Downregulation of a PathogenResponsive Tobacco UDP-Glc:Phenylpropanoid Glucosyltransferase Reduces Scopoletin Glucoside Accumulation, Enhances Oxidative Stress, and Weakens Virus Resistance. The Plant Cell. 2002;14(5):1093-1107.

Cusidó RM, Palazón J, Navia-Osorio A, Mallol A, Bonfill M, Morales C, et al. Production of Taxol® and baccatin III by a selected Taxus baccata callus line and its derived cell suspension culture. Plant Science. 1999;146(2):101-107.

Dandin V, Naik P, Murthy H, Park S, Lee E, Paek K. Rapid regeneration and analysis of genetic fidelity and scopoletin. Journal of Horticultural Science \& Biotechnology. 2014;89(1):79-85.

DAS M. Evaluation of the Laxative Effects of Methanolic Extract of Spilanthes acmella: East West University; 2014

Demarne F, Passaro G, inventors; Google Patents, assignee. Use of an Acmella Oleracea Extract for the Botox-Like Effect Thereof in an Anti-Wrinkle Cosmetic Composition patent US20080069912 A1. 2008.

Dixon RA. Natural products and plant disease resistance. Nature. 2001;411(6839):843-847.

Fett-Neto A, DiCosmo F. Production of paclitaxel and related taxoids in cell cultures of Taxus cuspidata: perspectives for industrial applications. In: DiCosmo F, Misawa M, editors. Plant Cell Culture Secondary Metabolism Toward Industrial Application. New York, USA: CRC Press; 1996. p. 139-66. 
Gachon C, Baltz R, Saindrenan P. Over-expression of a scopoletin glucosyltransferase in Nicotiana tabacum leads to precocious lesion formation during the hypersensitive response to tobacco mosaic virus but does not affect virus resistance. Plant Molecular Biology. 2004;54(1):137-146.

Heble MR. Multiple shoot cultures: a viable alternative in vitro system for the production of known new biologically active plant constituents. In: Neumann KH, Barz W, Reinhard E, editors. Primary and Secondary Metabolism of Plant Cell Cultures. Germany: Springer Science \& Business Media; 1985. p. 377.

Hudson T. Women's Encyclopedia of Natural Medicine: Alternative Therapies and Integrative Medicine for Total Health and Wellness: MACMILLAN HEINEMANN; 2007.

Kayser O, Quax WJ. Medicinal Plant Biotechnology: From Basic Research to Industrial Applications. Wiley-Blackwe. 2007. p. 187-199.

Moreno PRH, van der Heijden R, Verpoorte R. Effect of terpenoid precursor feeding and elicitation on formation of indole alkaloids in cell suspension cultures of Catharanthus roseus. Plant Cell Reports. 1993;12(12):702-705.

Morgan JA, Shanks JV. Determination of metabolic rate-limitations by precursor feeding in Catharanthus roseus hairy root cultures. Journal of Biotechnology. 2000;79(2):137-145.

Mukherjee S, Ghosh B, Jha S. Enhanced forskolin production in genetically transformed cultures of Coleus forskohlii by casein hydrolysate and studies on growth and organisation. Biotechnology Letters. 2000;22(2):133-136.

Murashige T, Skoog F. A revised medium for rapid growth and bio assays with tobacco tissue cultures. Physiologia Plantarum. 1962;15(3):473-497.

Namdeo AG. Investigation on pilot scale bioreactor with reference to the synthesis of bioactive compounds from cell suspension cultures of Catharanthus roseus Linn. . India: Devi Ahilya Vishwavidyalaya, Indore (MP); 2004.

Oksman-Caldentey K-M, Inzé D. Plant cell factories in the post-genomic era: new ways to produce designer secondary metabolites. Trends in Plant Science. 2004;9(9):433-440.

Ouyang J, Wang X-d, Zhao B, Wang Y-c. Enhanced production of phenylethanoid glycosides by precursor feeding to cell culture of Cistanche deserticola. Process Biochemistry. 2005;40(11):3480-3484.

Pandey V, Agrawal V, Raghavendra K, Dash AP. Strong larvicidal activity of three species of Spilanthes (Akarkara) against malaria (Anopheles stephensi Liston, Anopheles culicifacies, species C) and filaria vector (Culex quinquefasciatus Say). Parasitology Research. 2007;102(1):171-174.
Ramachandra Rao S, Ravishankar GA. Plant cell cultures: Chemical factories of secondary metabolites. Biotechnology Advances. 2002;20(2):101-153.

Schubnel L. A different approach to lifting efficacy based on a natural active ingredient. SÖFW-Journal. 2007;133(9).

Shimada T, Gomi T. Spilanthol-rich essential oils for manufacturing toothpastes or other oral compositions. JP Pat. 1995;7090294.

Shinde AN, Malpathak N, Fulzele DP. Enhanced production of phytoestrogenic isoflavones from hairy root cultures of Psoralea corylifolia L. using elicitation and precursor feeding. Biotechnology and Bioprocess Engineering. 2009;14(3):288-294.

Singh M, Chaturvedi R. Improved clonal propagation of Spilanthes acmella Murr. for production of scopoletin. Plant Cell Tiss Organ Cult. 2010;103(2):243-253.

Singh M, Chaturvedi R. Screening and quantification of an antiseptic alkylamide, spilanthol from in vitro cell and tissue cultures of Spilanthes acmella Murr. Industrial Crops and Products. 2012;36(1):321-328.

Taguchi G, Yoshizawa K, Kodaira R, Hayashida N, Okazaki M. Plant hormone regulation on scopoletin metabolism from culture medium into tobacco cells. Plant Science. 2001;160(5):905-911.

Tanton DW. A Drug-Free Approach To Healthcare 2009 Revised Edition: Soaring Heights Publishing; 2008. 356 p.

Wang C, Wu J, Mei X. Enhancement of taxol production and excretion in Taxus chinensis cell culture by fungal elicitation and medium renewal. Applied Microbiology and Biotechnology. 2001;55(4):404-410.

Woerdenbag HJ, Lüers JF, van Uden W, Pras N, Malingré TM, Alfermann AW. Production of the new antimalarial drug artemisinin in shoot cultures of Artemisia annua L. Plant Cell, Tissue and Organ Culture. 1993;32(2):247-257.

Wu J, Wong K, Ho K, Zhou L. Enhancement of saponin production in Panax ginseng cell culture by osmotic stress and nutrient feeding. Enzyme and Microbial Technology. 2005;36(1):133-138.

Yoganarasimhan SN. Medicinal Plants of India. India: Interline Publishing Private Limited; 2000. 513 p.

Received: December 22, 2015; Accepted: February 15, 2016. 